\title{
CIRPÉE
}

Centre interuniversitaire sur le risque, les politiques économiques et l'emploi

Cahier de recherche/Working Paper 03-35

\section{Equity and Policy Effectiveness with Imperfect Targeting}

\author{
Sami Bibi \\ Jean-Yves Duclos
}

Septembre/September 2003

Bibi: CIRPÉE and Faculté des Sciences Économiques et de Gestion de Tunis, Campus Universitaire, Bd. 7 Nov., El Manar, C.P. 2092, Tunis, Tunisia; fax: 216-71-93-06-15

samibibi@gnet.tn

Duclos: Département d'économique and CIRPÉE, Pavillon DeSève, Université Laval, Québec, Canada G1K 7P4; fax: 1-418-656-7798; phone: 1-418-656-7096

jyves@ecn.ulaval.ca

This research was partly funded by Canada's SSHRC, Québec's FQRSC, and the PEP Programme of the International Development Research Centre. We are grateful to Jean-Michel Grandmont and Philip Merrigan for their useful comments. 
Abstract: We propose a general cost-of-inequality approach that jointly integrates horizontal and vertical equity criteria in the assessment of poverty alleviation programs, with the strength of each criterion being captured through its own inequityaversion parameter. This contrasts with the assessment of poverty alleviation programs done with simple under-coverage and leakage ratios or with other methods that do not take into account the heterogeneity of the poor and that do not address directly the social benefits of achieving normative criteria. Our methodology is illustrated using Tunisia data and two alternative poverty alleviation policies. We find inter alia that the social ranking of commodity and socio-demographic targeting in Tunisia depends on the policymaker's comparative preference for vertical and horizontal equity.

Keywords: Poverty, Vertical Equity, Horizontal Inequity, Transfers, Targeting, Tunisia

JEL Classification: D12, D63, H53, I32, I38 


\section{Introduction}

Attempts to target public transfers efficiently are typically constrained by the lack of information that government agencies have on the welfare of individuals and households, and this is particularly true in less developed countries. Policymakers are thus forced to select among imperfect targeting schemes to choose recipients and non-recipients of public support. Such choices can be made based on indirect individual indicators of welfare (such as geographic location, socio-demographic characteristics, land ownership, or type of housing), through differentiated indirect taxation (such as foodstuff subsidization), or through "self-targeting" schemes (such as subsidized low-wage public employment).

It has been common practice in the literature to describe the effectiveness and the equity of these policies using mainly two types of indicators ${ }^{1}$. These are linked to the presence of Type I and Type II errors. Type I errors arise from "false negatives" or exclusion errors, that is, they arise when eligible or poor families are not awarded a transfer. Type II errors come from "false positives" or inclusion errors, which occur when benefits are wrongly awarded to the non-poor or to the non-eligible. Quoting from Weisbrod (1970),

Two issues are involved, having to do with the accuracy of the program in assisting only the "target" group, and the comprehensiveness of the program in assisting all of that group. (p. 125)

It is usually argued that inclusion errors reduce the vertical efficiency of the programs - by failing to distinguish appropriately between the poor and the non poor - and that exclusion errors lead to horizontal inefficiency, since these errors discriminate among the poor.

To describe the importance of these errors, leakage and under-coverage rates are often computed. Rates of leakage are typically defined as the proportion of total transfers going to the pre-transfer non-poor ${ }^{2}$. Definitions of under-coverage rates vary, but are usually linked to the ratio of the number of beneficiaries in a target group (e.g., the poor) to the total number of persons in that group. Clearly, however, leakage and under-coverage rates are incomplete indicators of the impact of social programs on poverty. As Ravallion and Datt (1995, p. 415), put it, "the ability of a policy to concentrate benefits on the poor should not be confused

\footnotetext{
${ }^{1}$ For recent examples, see for instance Cornia and Stewart (1995), Duclos (1995), and Schady (2002).

${ }^{2}$ See for example Weisbrod (1970), Beckerman (1979), Atkinson (1995), Creedy (1996).
} 
with its impact on poverty; the former is only one determinant of the latter." An important reason for this is that the poor often differ considerably from each other in many respects, including welfare. Sen's (1976) influential paper has clearly argued why such differences should matter for poverty measurement ${ }^{3}$. Logically, they should also matter for assessing the poverty effectiveness of policies and programs. One motivation for this is well summarized by Grosh and Baker (1995):

While it is unsatisfactory to fail to cover those who fall below the poverty line, the error is less grave if the people who are excluded fall only just below the poverty line rather than at the very bottom of the welfare distribution. (p. 13)

Thus, the use of exclusion errors and under-coverage ratios will often fail to present a distribution-sensitive picture of the impact of programs on the poor ${ }^{4}$. Grosh and Baker (1995) go on arguing that

The best way to judge whether the levels and trade-offs between undercoverage and leakage are acceptable is to calculate the changes in the poverty indices that result from the different models. The model that reduces poverty the most given a fixed budget is the most acceptable. (p. 13)

This is precisely the approach we will follow in this paper. In doing this, we will, however, also outline a general method that brings distribution-sensitivity formally into the study of the poverty impact of social programs. An important objective of the paper is to highlight the role and the presence of horizontal equity, whose worthiness as a moral goal is virtually unanimously recognized but which has been typically neglected in policy discussions of targeting and policy alleviation issues. In comparing poverty before and after a policy, or across two policies, we will thus account for the role of three summary indicators:

- The first indicator is the rate of leakage, defined as in the earlier studies. This will capture how much of a program's resources are "wasted" on the non-poor. This indicator is only affected by the assumed demarcation between the poor and the non-poor - it is not sensitive to the distribution of the policy impact among the poor.

\footnotetext{
${ }^{3}$ On this, see also among many others Foster (1984), Foster, Greer and Thorbecke (1984), Atkinson (1987), Foster and Shorrocks (1988), Ravallion (1994), Jenkins and Lambert (1997), and Zheng (1997).

${ }^{4}$ See Park et al. (2002) for one attempt at constructing such indicators in a distribution-sensitive way.
} 
- The second indicator is a measure of the vertical equity (VE) of the programs. VE demands a search for a reduction in the welfare gaps that separate unequal individuals. This second indicator will capture the extent to which vertical inequality in the distribution of poverty gaps is reduced by a program, and also therefore the extent to which errors of exclusion affect more the not-so-poor than the very poor.

- The third indicator captures the horizontal equity (HE) of a program. Our definition of HE will be in line with the traditional or "classical" HE approach, which defines HE as "the equal treatment of equals" (see Musgrave, 1959). There is horizontal inequity (HI) when equals are treated unequally.

The combination of the above three indicators captures the trade-off between the usual targeting accuracy (leakage), VE and HI components. As we will see, this information can be useful for descriptive as well as for policy design purposes.

Note again that the leakage and under-coverage rates used in earlier studies are not sensitive to the distribution among the poor of the impact of targeting errors. The exclusion of a very poor counts in exactly the same way as the exclusion of a not-so-poor, which thus contradicts a basic property for a proper VE indicator. Moreover, neither of these rates is truly horizontal since neither captures whether pre-program welfare-similar poor are treated the same way by the program.

Instead, this paper uses local HI indicators that assess whether the same treatment is granted to all of the poor of the same pre-program welfare level ${ }^{5}$. The starting point for the computation of $\mathrm{HI}$ is the "local" dispersion of post-policy poverty gaps among individuals having the same pre-policy poverty gap. Aggregation of these local dispersion indicators across welfare levels leads to a global HE indicator.

In decomposing the change in poverty caused by a program, we further import to poverty measurement the concept of the "cost of inequality" - a concept that has been very influential in the literature on inequality measurement (see Kolm, 1969, and Atkinson, 1970). The poverty-alleviation effectiveness of a policy is then a function of the leakage that it involves and of the change in the cost of inequality that it causes. For this, the poverty measures to be used will naturally gain from being distribution sensitive $e^{6}$. This change in the cost of inequality is

\footnotetext{
${ }^{5}$ Ravallion (1998) uses an analogous idea, but at an aggregate level: he captures horizontal inequity in China by the difference in expected program allocation between two departments (of a given province) with the same poverty measure.

${ }^{6}$ See Zheng (1997) on this.
} 
then further decomposed into VE and HI components. To take HI seriously and to grant it an ethical importance that is distinct from that of increasing the vertical distances between individuals, we need to allow the aversion towards vertical inequality to differ from that towards the horizontal inequality introduced by a social program, in the manner for instance of Auerbach and Hasset (2002) for the analysis of inequality and social welfare. We therefore assign VE and HE each its own inequity-aversion parameter.

One of the main uses of this paper's methodological development would certainly seem to be to examine whether program reforms could be implemented to alleviate poverty further and better. We illustrate this using micro-data from the 1990 Tunisian Household Expenditure Survey. In doing this, we make use of non-parametric estimation procedures to assess the extent of VE and HI. We ask whether it would be poverty effective to substitute a direct transfer program based on socio-demographic proxy means-tests - to the current universal food subsidy system - "commodity targeting" - currently in place in Tunisia. We find that socio-demographic targeting would generate significantly more $\mathrm{HI}$, although it would display a lower leakage rate and a greater VE than the current commodity-targeting program. Hence, whether one is socially preferable to the other depends on the policymaker's parameters of vertical and horizontal inequity aversion.

The rest of the paper is structured as follows. Section 2 situates and motivates this paper's analysis of HE. Section 3 presents the measurement techniques. Section 4 discusses the statistical procedures to be used to apply these techniques. Section 5 applies the methodology to the 1990 Tunisian household survey, and Section 6 concludes.

\section{Horizontal equity in theory and in practice}

Taking HE into account would seem to matter both in theory and in practice. On the one hand, there is virtual consensus among analysts on the moral importance of the HE criterion. On the other hand, because households' preferences and characteristics are heterogeneous, and because the impact of most forms of public intervention is intrinsically non-deterministic, social programs and economic policy will commonly generate violations of HE. We consider each of these two issues in turn. 


\subsection{Horizontal equity in theory}

Recall that the classical definition of HE is that equals should be treated equally. While this principle is generally well accepted, different rationales have been advanced to support it. First, a policy which discriminates across comparable individuals is liable to create resentment and insecurity, possibly also leading to social instability. This is supported by the socio-psychological literature which shows that exclusion and discrimination have an impact both on individual well-being and on social cohesion and welfare. Second, the search for vertical redistribution, which is a key objective of many programs and policies, is generally undermined by $\mathrm{HI}$ since HI pulls equals apart. Hence, a desire for HE can simply derive from an aversion to inequality, without invoking a separate normative basis for HE.

Third, HE can also be argued to be an ethically more robust moral criterion than VE. Depending on one's ethical attitude towards distributive fairness, the implications in terms of vertical justice can vary considerably, but the principle of HE would appear to remain essentially invariant across analysts (Musgrave, 1990). This has led several authors (including Stiglitz, 1982, Balcer and Sadka, 1986 and Hettich, 1983) to advocate a separate moral treatment for HE. HE should then be treated and assessed separately from VE, and should form a criterion on its own in analyzing the trade-off between two policies. As in all trade-offs, it is clear that violations of $\mathrm{HE}$ are often inevitable (although still regrettable), such as when some forms of behavior are encouraged for economic efficiency or VE reasons. One goal of this paper is to show how the terms of this trade-off can be weighted in practice.

There would also seem to exist some "micro" foundations for HE. For example, the theory of relative deprivation (which is well documented in the sociopsychological literature) suggests that people often specifically compare their relative individual fortune with that of others in similar or close circumstances. In a discussion of the post-war British welfare state, Runciman (1966) notes for instance that

the reference groups of the recipients of welfare were virtually bound to remain within the broadly delimited area of potential fellow-beneficiaries. It was anomalies within this area which were the focus of successive grievances, not the relative prosperity of people not obviously comparable.(p.71)

Similarly, in his theory of social comparison processes, Festinger (1954) argues that "given a range of possible persons for comparison, someone close to one's 
own ability or opinion will be chosen for comparison" (p.121).

It must be said that, although widely recognized, the value of studying $\mathrm{HE}$ has not always been universally accepted. There are two reasons for this. The first is that utilitarianism and the Pareto principle may justify the unequal treatment of equals ${ }^{7}$. King (1983a) and others see, however, this implication as a flaw of strict utilitarianism since it ignores the fairness of the redistributive process. A number of authors have also questioned the empirical feasibility of studying classical HE since no two individuals are ever exactly alike in a finite sample ${ }^{8}$. The proposed alternative was then to focus on re-ranking 9 . We choose not to follow the reranking approach here, for two reasons. First, we do address the above-mentioned feasibility problem below. Second, it can be argued (see King, 1983a, and Duclos et al., 2002) that absence of re-ranking and classical HE are logically equivalent equity criteria, although the measure of their respective violations can of course differ. Hence, we focus in this paper on the study of classical HI as opposed to re-ranking, although as shown in Duclos et al. (2002) the two approaches could be integrated in a single framework, but at some cost in terms of expositional simplicity.

\subsection{Horizontal equity in practice}

Violations of HE seem to abound in practice. As mentioned briefly above, the reasons are many and are due largely to household heterogeneity, informational problems, administrative errors, randomness in the effect of programs and policies, and outright discrimination. A good example of the latter is given by Narayan and Petesch (2002):

Despite official rules that make discrimination illegal, behavior by state, market, and civic institutions reflects prejudice against poor people, women, and excluded social groups. (...) Excluded social groups include the Roma in Bulgaria, the low castes and untouchables in India, "the hated poor" in Bangladesh, indigenous and AfroAmerican groups in Latin America, and slum dwellers everywhere. (...) Poor people reported that government service providers invariably reach the rich over the bodies of the poor. In India the rich get

\footnotetext{
${ }^{7}$ See for instance Kaplow $(1989,1995)$.

${ }^{8}$ See inter alia Feldstein (1976), and Plotnick $(1982,1985)$.

${ }^{9}$ This is nicely discussed in the survey by Jenkins and Lambert (1999) and by Plotnick's (1999) comments on it.
} 
to the front of the line for services even when poor people have been waiting for hours. In several places people said that service providers first look at their face, name, or address and then decide whether they deserve any attention. Poor people also experience discriminatory behavior from members of society at large. (p. 479-480)

Other sources of HI appear to be more subtle. Several recent studies suggest that the case of Chinese inter-provincial and intra-provincial (inter-country) allocations of funds provides an interesting case of "official" discrimination. Officially, transfer-recipient countries are chosen according to whether mean country income falls below some threshold. These thresholds, however, sometimes vary arbitrarily across regions. Indeed, Park et al. (2002) "find that political factors have influenced the selection of poor countries. (...) Initial designations favored minority and revolutionary base areas, were not equitable across provinces, and were affected by lobbying efforts" (p. 125). Besides, there is poor targeting at sub-country level, for political and administrative reasons.

Ravallion (1998, p.27) also concludes that decentralization generated substantial "horizontal inequality" in public spending on poor areas. Interestingly, he suggests that "the allocation to a province should depend not only on how poor the province is, but on how successful it is at discriminating in favor of poor areas." This would help in reducing HI within provinces. Jalan and Ravallion (1998) also report that, in the late 1980's, about half of the poor people in four Southern provinces did not live in the countries officially designated poor by the Chinese government (see also Riskin, 1994). This is clearly another example of unequal treatment across poor of similar welfare levels. ${ }^{10}$

Indirect transfers provide another source of HI. For instance, Adams (2000) reports that, in urban Egypt, the main subsidized food - coarse baladi bread is consumed more by the poor than by the non-poor. The food subsidy system would thus appear somewhat self-targeted to the urban poor, since it subsidizes "inferior" goods. Relative to lump-sum transfers, the system therefore involves a lower leakage and a greater VE among the urban population. But the rural poor consume less of baladi bread than the urban poor. They also have a lower baladi consumption than the rural non-poor, and thus receive less in food subsidy than those rural non-poor. Hence, not only is the baladi subsidy less vertically effective in rural areas, it also introduces HI between the rural and urban poor.

Clearly, these issues are policy-relevant in the context of many other developing (and developed) countries. They will also arise in the Tunisian case to be

\footnotetext{
${ }^{10}$ A similar story seems to hold for Indonesia's regional disbursements - see Ravallion (1993).
} 
examined in Section 5, using the methodology that we are now going to develop.

\section{Measuring poverty and equity}

\subsection{Poverty and inequality}

Consider a vector $\mathbf{y}=\left(y_{1}, y_{2}, \ldots, y_{N} ; n_{1}, n_{2}, \ldots, n_{N}\right)$ of living standards $y_{h}$ (incomes, for short) for a population of $n=\sum_{h=1}^{N} n_{h}$ individuals. Let the poverty line be denoted as z. A useful tool in this paper will be that of poverty gaps, defined for an individual at $y_{h}$ as

$$
g_{h}(z)=\max \left(z-y_{h}, 0\right) .
$$

$\mathbf{g}(z)=\left(g_{1}(z), \ldots, g_{N}(z) ; n_{1}, n_{2}, \ldots, n_{N}\right)$ is then the vector of poverty gaps. Many of the common poverty measures can be expressed in terms of poverty gaps ${ }^{11}$. An important subset of these measures is the class of the FGT (Foster, Greer and Thorbecke, 1984) additively decomposable indices, which are defined as: 12

$$
P_{\alpha}(\mathbf{g}(z))=n^{-1} \sum_{h=1}^{N} n_{h} g_{h}(z)^{\alpha}
$$

where $\alpha$ may be considered as a measure of aversion to inequality among the poor: a larger $\alpha$ gives a greater weight to a loss of income to the poorest than to the not-so-poor. When $\alpha$ becomes very large, $P_{\alpha}(\mathbf{g}(z))$ approaches a Rawlsian measure, which essentially depends only on the poorest individual's income. ${ }^{13}$ These poverty measures are non increasing in $y_{h}$ and are symmetric or anonymous with regard to individual incomes. $P_{0}(\mathbf{g}(z))$ gives the headcount ratio, which is well-known for being inter alia insensitive to falls in the welfare of the poor. $P_{1}(\mathrm{~g}(z))$ yields the average poverty gap, which is not sensitive to the distribution of well-being among the poor. When $\alpha>1$, however, the $P_{\alpha}(\mathbf{g}(z))$ are strictly

\footnotetext{
${ }^{11}$ On this, see for instance Jenkins and Lambert (1997). Note that focussing on poverty gap measures is not needed for the analysis, although it simplifies the exposition. The same is true for the use of the FGT indices in the paper: other additive indices, such as the Watts (1968) index, could equally be used.

${ }^{12}$ The indices in (2) are non-normalized FGT indices, and are used here for expositional simplicity (see also inter alia Chakravarty and Mookherjee (1998)). The normalized version is defined in terms of relative poverty gaps, $g_{h}(z) / z$.

${ }^{13}$ See Rawls (1971).
} 
convex in $y_{h}$, and this ensures that an equalizing transfer of income from a poor person to anyone who is poorer decreases $P_{\alpha}(\mathrm{g}(z))$, thus making these indices distribution sensitive.

A simple monotonic transformation of $P_{\alpha}(\mathrm{g}(z))$ leads to a useful moneymetric measure of poverty. In the manner of Atkinson (1970) for the measurement of social welfare and inequality, let $\Gamma_{\alpha}(\mathrm{g}(z))$ be the "equally-distributed equivalent (EDE) poverty gap", viz, that poverty gap which, if assigned equally to all individuals, would produce the same poverty measure as that generated by the actual distribution of poverty gaps. Using (2), $\Gamma_{\alpha}(\mathbf{g}(z))$ is given implicitly for $\alpha>0$ as

$$
\Gamma_{\alpha}(\mathbf{g}(z))^{\alpha} \equiv P_{\alpha}(\mathbf{g}(z))
$$

and thus we have

$$
\Gamma_{\alpha}(\mathbf{g}(z))=P_{\alpha}(\mathbf{g}(z))^{\frac{1}{\alpha}} \text { for } \alpha>0 .
$$

Note that $\Gamma_{1}(\mathrm{~g}(z))$ is the average poverty gap. Sen's (1976) $N$ axiom argues that this is an adequate poverty measure only if all the poor have the same income. Otherwise, using $\Gamma_{1}(g(z))$ will fail to capture the inequality in the distribution of poverty (as distinct from its average intensity). This argues that $\Gamma_{\alpha}(g(z))$ should in general be greater than $\Gamma_{1}(g(z))$ in order for $\Gamma_{\alpha}(g(z))$ to be sensitive to the presence of inequality among the poor. This is achieved only when $\alpha$ is strictly greater than 1, which we therefore impose as a condition on the indices in (2).

Whenever all have the same poverty gap, $\Gamma_{\alpha}(\mathbf{g}(z))=\Gamma_{1}(\mathbf{g}(z))$ whatever the value of a positive $\alpha$. A mean-preserving increase in the spread between a poor person and someone less poor will increase $\Gamma_{\alpha}(\mathbf{g}(z))$. Thus, for a given $\alpha$, the more important the difference between $\Gamma_{\alpha}(\mathbf{g}(z))$ and $\Gamma_{1}(\mathbf{y}, z)$, the more unequal we can think the distribution of poverty gaps to be. An obvious measure of the cost of inequality in the distribution of poverty gaps is then given by:

$$
C_{\alpha}(\mathbf{g}(z))=\Gamma_{\alpha}(\mathbf{g}(z))-\Gamma_{1}(\mathbf{g}(z)) \text { for } \alpha \geq 1 .
$$

Note that $C_{\alpha}(\mathbf{g}(z))$ is given in per capita money-metric terms, which makes it directly comparable to $\Gamma_{1}(\mathbf{g}(z))$. It is always non-negative. It can also be shown to be a natural transposition of the cost-of-inequality approach proposed by Atkinson (1970) in the context of social welfare to a case in which the incomes of all the non-poor have been set equal to $z$. Rewriting (5), total poverty can be expressed as:

$$
\Gamma_{\alpha}(\mathbf{g}(z))=\Gamma_{1}(\mathbf{g}(z))+C_{\alpha}(\mathbf{g}(z)), \alpha \geq 1
$$


This is illustrated in Figure 1. It shows a distribution of 2 poverty gaps, $g_{1}(z)$ and $g_{2}(z)$ (measured along the horizontal scale), the poverty index $P_{\alpha}(\mathbf{g}(z))$ for that distribution, the average poverty gap $\Gamma_{1}(\mathrm{~g}(z))$, and the EDE poverty gap $\Gamma_{\alpha}(\mathbf{g}(z))$. Note that $\Gamma_{1}(\mathbf{g}(z))$ is the average of $g_{1}(z)$ and $g_{2}(z)$, and that $\left(\Gamma_{\alpha}(\mathbf{g}(z))\right)^{\alpha}=P_{\alpha}(\mathbf{g}(z))$ is the average of $g_{1}(z)^{\alpha}$ and $g_{2}(z)^{\alpha}$. The cost of inequality is the horizontal distance between $\Gamma_{1}(\mathbf{g}(z))$ and $\Gamma_{\alpha}(\mathrm{g}(z))$.

Note that it is only when the poverty gaps are equally distributed across the total population that the cost of inequality becomes zero. For $\alpha>1, C_{\alpha}(\mathbf{g}(z))$ will be positive so long as at least one member of the population is non-poor and one other is poor, even if all of the poor have the same income. Note that this differs from the implication of Sen's (1976) $N$ axiom which deals with inequality only among the poor.

\subsection{Targeting and equity}

Now consider two policy regimes, one which leads to an income distribution $\mathbf{y}^{1}$ and a second which generates $\mathbf{y}^{2}$, with respective $y_{h}^{i}, g_{h}^{i}(z)$ and $\mathbf{g}^{i}(z), i=1,2$. For expositional and analytical simplicity, we will assume that these two regimes are overall-budget-neutral for the government, and that both cost a per capita amount of $\rho$.

\subsubsection{Leakage}

For each regime, the average poverty gap, $\Gamma_{1}(\mathbf{g}(z))$, is decreased by a per capita amount given by $\rho$ minus the per capita leakage of the benefit. This leakage is given for policy $i$ by

$$
L^{i}(z)=\rho-\left(\Gamma_{1}(\mathbf{g}(z))-\Gamma_{1}\left(\mathbf{g}^{i}(z)\right) .\right.
$$

The leakage can arise from benefit spills onto the non-poor, but as in Creedy (1996) $L^{i}(z)$ also includes the value of the transfers that raise the pre-policy poor above the poverty line. Note also that $L^{i}(z)$ can be affected by the presence of some economic-efficiency-benefits and economic-inefficiency-costs of the policy. It is therefore not theoretically bounded by 0 or by $\rho$. Note further that $\rho$ will be negative if the policy raises positive tax revenues. In that case, $L^{i}(z)$ will be negative and lower in absolute value than $\rho$, indicating that a part of the tax is borne by the non-poor.

$L^{i}(z)$ captures policy $i$ 's ability to award benefits to the poor people, regardless of their poverty level. Since the poor can vary greatly in these poverty levels, 
leakage can only be one of the determinants of the social impact of a poverty alleviation policy.

\subsubsection{Horizontal equity}

The "equals" that the HE principle requires to treat alike (Feldstein, 1976) are typically considered to be those with the same utility. Since utility is difficult to infer, a natural approximation would seem to be to consider as equals those having the same pre-reform standard of living, or, said differently, those with the same income (suitably adjusted, if need be, for differences in individual needs, family composition, and prices faced). In the context of the analysis of povertyalleviation effectiveness, another natural assumption would be that the HE principle would not take into account the variability of the treatment of the non-poor. ${ }^{14}$

For any fixed $y_{h}$ in pre-policy $\mathbf{y}$, let $\Omega\left(y_{h}\right)$ denote the group of persons having $y_{h}$ before the policy: this is the group of $n_{h}$ equals located at income $y_{h}$. The local presence of $\mathrm{HI}$ at $y_{h}$ generates post-policy inequality within the members of $\Omega\left(y_{h}\right)$. Let $\gamma_{\beta}^{i}\left(y_{h}, z\right)$ then be the post-reform EDE poverty gap at $y_{h}$, namely,

$$
\gamma_{\beta}^{i}\left(y_{h}, z\right)=\left(n_{h}^{-1} \sum_{\Omega\left(y_{h}\right)} g_{h}^{i}(z)^{\beta}\right)^{1 / \beta}
$$

Note that the overall average poverty gap is given by $\Gamma_{1}^{i}(z)=n^{-1} \sum_{h=1}^{N} n_{h} \gamma_{1}^{i}\left(y_{h}, z\right)$. Using the cost-of-inequality approach developed earlier, a natural measure of the local cost of HI (the local cost of inequality introduced by local HI) at $y_{h}$ is then given by:

$$
\eta_{\beta}^{i}\left(y_{h}, z\right)=\gamma_{\beta}^{i}\left(y_{h}, z\right)-\gamma_{1}^{i}\left(y_{h}, z\right) \geq 0 .
$$

The EDE gap $\gamma_{\beta}^{i}\left(y_{h}, z\right)$ can be interpreted as the HI-adjusted post-policy poverty gap. In a context of risk aversion in which individuals would be assumed to augment their post-policy expected poverty gap by a risk premium, this risk premium would be given by $\eta_{\beta}^{i}\left(y_{h}, z\right)$, and their risk-adjusted poverty status would thus be given by $\gamma_{\beta}^{i}\left(y_{h}, z\right)=\eta_{\beta}^{i}\left(y_{h}, z\right)+\gamma_{1}^{i}\left(y_{h}, z\right)$. $\eta_{\beta}^{i}\left(y_{h}, z\right)$ can thus be interpreted as

\footnotetext{
${ }^{14}$ This latter assumption would seem relatively uncontroversial here, but may not be appropriate in the more general context in which a policy can tax incomes as well as supplement them. HI among the initially non-poor could then easily bring some of them underneath the poverty line. The cost of HI among the initially non-poor would then enter through the increase in poverty generated by these discriminated non-poor.
} 
the local welfare cost of HI, a welfare cost which adds to the post-policy average poverty gap of those individuals at $y_{h}$.

An obvious next step is to aggregate the $\eta_{\beta}^{i}\left(y_{h}, z\right)$ across the $y_{h}$. Using population shares to do this ${ }^{15}$, an aggregate index of $\mathrm{HI}$ is simply obtained as:

$$
H_{\beta}^{i}(z)=n^{-1} \sum_{h=1}^{N} n_{h} \eta_{\beta}^{i}\left(y_{h}, z\right) .
$$

\subsubsection{Vertical equity}

Let us now focus on the distribution of the local EDE poverty gaps $\gamma_{\beta}^{i}\left(y_{h}, z\right)$. As argued above, this distribution is arguably a good indicator of individual welfare in the presence of horizontal inequity and risk. Denote this distribution as $\gamma_{\beta}^{i}(z)=$ $\left(\gamma_{\beta}^{i}\left(y_{1}, z\right), \ldots, \gamma_{\beta}^{i}\left(y_{N}, z\right) ; n_{1}, n_{2}, \ldots, n_{N}\right)$. The cost of inequality with $\gamma_{\beta}^{i}(z)$ is then given by

$$
C_{\alpha}\left(\gamma_{\beta}^{i}(z)\right)=\Gamma_{\alpha}\left(\gamma_{\beta}^{i}(z)\right)-\Gamma_{1}\left(\left(\gamma_{\beta}^{i}(z)\right)\right.
$$

$C_{\alpha}\left(\gamma_{\beta}^{i}(z)\right)$ can then be interpreted as the cost of inequality of a post-policy distribution in which everyone is attributed his risk-adjusted poverty gap. The VE of that policy can presumably be measured by the difference between that cost and the initial cost of inequality. In other words, we can define the VE of policy $i$ as:

$$
V_{\alpha, \beta}^{i}(z)=C_{\alpha}(\mathbf{g}(z))-C_{\alpha}\left(\gamma_{\beta}^{i}(z)\right) .
$$

Ceteris paribus, the larger the value of $V_{\alpha, \beta}^{i}(z)$, the more vertically equitable is policy $i$.

\subsection{Overall policy effectiveness}

As argued in the introduction, a natural measure of the poverty effectiveness of a policy is given by the fall in poverty that results from moving from the pre-policy distribution of poverty gaps, $\mathrm{g}(z)$, to the post-policy distribution of EDE poverty gaps, $\gamma_{\beta}^{i}(z)$. Policy effectiveness is thus given by:

$$
E_{\alpha, \beta}^{i}(z)=\Gamma_{\alpha}(\mathbf{g}(z))-\Gamma_{\alpha}\left(\gamma_{\beta}^{i}(z)\right)
$$

15 This ensures that $H_{\beta}^{i}(z)$ in $(10)$ is unaffected by vertical considerations, viz, it ensures that the importance attributed to some local HI does not depend upon the income level at which it is experienced - see Musgrave (1990). This across-group aggregation is analogous to that of Blackorby et al. (1981). It is also followed by Lambert and Ramos (1997), Duclos and Lambert (2000) and Bibi (2002a). 
The following then obtains.

Theorem 1 With degrees $\alpha$ and $\beta$ of preference for $V E$ and $H E$ respectively, the policy effectiveness of a policy $i$ is given by

$$
E_{\alpha, \beta}^{i}(z)=\rho-L^{i}(z)+V_{\alpha, \beta}^{i}(z)-H_{\beta}^{i}(z) .
$$

See appendix.

The policy effectiveness is thus a simple sum of budgetary outlay, the rate of leakage, and vertical and horizontal equity. Denote $\Delta E_{\alpha, \beta}(z)=E_{\alpha, \beta}^{2}(z)-E_{\alpha, \beta}^{1}(z)$ and define $\Delta L(z), \Delta V_{\alpha, \beta}(z)$ and $\Delta H_{\beta}(z)$ analogously.

Corollary 2 Assuming equal budgetary expenditures on policies 1 and 2, the difference in policy effectiveness between these two policies is given by:

$$
\Delta E_{\alpha, \beta}(z)=-\Delta L(z)+\Delta V_{\alpha, \beta}(z)-\Delta H_{\beta}(z) .
$$

Note that (15) shows clearly the nature of the trade-off that can emerge between targeting accuracy and vertical and horizontal equity. Clearly, policy 2 will be more effective $\left(\Delta E_{\alpha, \beta}(z)>0\right)$ if it involves a lower leakage of resources, a larger degree of VE and/or a lower degree of $\mathrm{HI}$ than policy 1. A policy can dominate another even with a higher leakage and a lower degree of vertical equity if it is horizontally more equitable. Note that the measure of leakage is independent of $\alpha$ and $\beta$ and is thus distribution-insensitive among the poor. Conversely, VE and $\mathrm{HI}$ are distribution sensitive and do depend on the inequity-aversion parameters $\alpha$ and $\alpha$.

The following interpretive remarks should be useful (the proofs of most the assertions are proved in the appendix).

1. $\beta$ can be usefully interpreted as the degree of aversion to HI within groups of local equals, and $\alpha$ as the degree of aversion to inequality across these groups.

2. When $\alpha=\beta=1, V_{1,1}^{i}(z)=H_{1}^{i}(z)=0$, which also says that differences in policy effectiveness then depend solely on differences in benefit leakage.

3. When $\alpha=\beta$, HI counts in the policy assessment only in so much as it adds to the vertical distances between individuals. No separate ethical aversion towards HI appears. We then have:

$$
C_{\alpha}(\mathbf{g}(z))-C_{\alpha}\left(\mathbf{g}^{i}(z)\right)=V_{\alpha, \alpha}^{i}(z)-H_{\alpha}^{i}(z) .
$$


Vertical equity minus horizontal inequity explains entirely the change in the cost of inequality between the pre- and post-policy distributions of poverty gaps. $H_{\alpha}^{i}(z)$ again matters only in as much as it adds to the cost of inequality in $\mathbf{g}^{i}(z)$. From this, it also follows that

$$
E_{\alpha, \alpha}^{i}(z)=\rho-L^{i}(z)+C_{\alpha}(\mathbf{g}(z))-C_{\alpha}\left(\mathbf{g}^{i}(z)\right)
$$

and

$$
\Delta E_{\alpha, \alpha}(z)=-\Delta L(z)+C_{\alpha}\left(\mathbf{g}^{1}(z)\right)-C_{\alpha}\left(\mathbf{g}^{2}(z)\right) .
$$

4. The case in which $\alpha$ and $\beta$ are equal is clearly a special one. Indeed, in the words of Auerbach and Hasset (2002, p.1116), "if horizontal equity is to have any independent content, it seems both necessary and appropriate for attitudes to differ about these two types of inequality". There are two other possible cases. To consider them, assume that $\mathrm{HI}$ affects the incomes of at least some of the poor.

(a) Whenever $\alpha<\beta$, HI has an adverse policy impact in excess of its widening of the distances between individuals. In such instances, it follows that distributive effectiveness $\left(V_{\alpha, \beta}^{i}(z)-H_{\beta}^{i}(z)\right)$ is then judged inferior to the change in the cost of inequality:

$$
V_{\alpha, \beta}^{i}(z)-H_{\beta}^{i}(z)<C_{\alpha}(\mathbf{g}(z))-C_{\alpha}\left(\mathbf{g}^{i}(z)\right) .
$$

(b) By setting $\beta<\alpha$, it is also possible for a policy analyst to discard, downplay or hide HI and the dispersion introduced by it. In such cases, distributive effectiveness is then judged superior to the change in the cost of inequality:

$$
V_{\alpha, \beta}^{i}(z)-H_{\beta}^{i}(z)>C_{\alpha}(\mathbf{g}(z))-C_{\alpha}\left(\mathbf{g}^{i}(z)\right) .
$$

The particular case of setting $\beta=1$ is in fact equivalent to replacing all post-policy poverty gaps by their expected value (conditional on their pre-policy initial value). This is in fact what is done when policy simulation analysis is performed assuming that the impact of a policy can depend only on pre-policy income - assuming away all other factors of variability.

5. Observe that the result in (14) makes it possible to be averse to HI even in the absence of a preference for $\operatorname{VE}$ (viz, when $\beta>\alpha=1$ ). This could 
describe the ethical attitude of "contractarian" policymakers (see, for instance, Nozick, 1974), who are typically more concerned with the fairness of a process than by its redistributive effect.

6. Finally, different ethical preferences towards VE and HE can imply different policy effectiveness judgements. This will be illustrated below. In fact, the greater the value of $\beta$, the closer the local post-policy EDE poverty gaps $\gamma_{\beta}^{i}\left(y_{h}, z\right)$ become to the poverty gap of the worst off in that local group of equals. As $\beta$ approaches infinity, policy effectiveness is assessed on the basis of a set of local Rawlsian judgements, viz, it is judged using the fate of the worst-off in each initial group of equals. This is shown by the fact that

$$
\lim _{\beta \rightarrow \infty} \gamma_{\beta}^{i}\left(y_{h}, z\right)=\max _{y_{h}^{i} \in \Omega\left(y_{h}\right)}\left\{\mathbf{g}^{i}(z)\right\}
$$

and that local horizontal inequity is then given by

$$
\lim _{\beta \rightarrow \infty} \eta_{\beta}^{i}\left(y_{h}, z\right)=\max _{y_{h}^{i} \in \Omega\left(y_{h}\right)}\left\{\mathbf{g}^{i}(z)\right\}-\gamma_{1}^{i}\left(y_{h}, z\right) .
$$

\subsection{Robustness of results}

The policy implications of the above methodology can potentially depend arbitrarily on the choice of a poverty line $z$ and of a poverty measure. The application of well-known results from the stochastic dominance literature shows, however, that (setting $\alpha=\beta$ ) if $\Delta E_{\alpha, \alpha}(z) \geq 0$ for a range of poverty lines that starts at 0 and extends to $z^{+}$, then policy 2 will necessarily be judged to reduce poverty by more than policy 1 for any choice of poverty line within $\left[0, z^{+}\right]$and for any choice of poverty index within a class of ethical order $\alpha+1.16$

For $\alpha=1$ (second-order poverty dominance), this test simply involves differences between the leakages of the two policies since we then have $\Delta E_{1,1}(z)=$ $-\Delta L(z)$. Since $\Delta E_{1,1}(z)=\rho-L^{2}(z)-\left(\rho-\Delta L^{1}(z)\right)$ The test can also be made using the difference between the cumulative benefits of policies 2 and 1 up to varying values of $z$. For tests of second-order dominance, the measures of HE and VE in (15) are therefore not (directly) relevant.

For third-order poverty dominance, one checks whether $\Delta E_{2,2}(z)=-\Delta L(z)+$ $\Delta V_{2,2}(z)-\Delta H_{2}(z) \geq 0$. Note that if for some $\alpha, \Delta E_{\alpha, \alpha}(z)$ is not of the desired

\footnotetext{
${ }^{16}$ See, for example, Atkinson (1987), Foster and Shorrocks (1988), Ravallion (1994) or Duclos and Makdissi (2002).
} 
sign over the specified range of poverty lines, one can focus on classes of poverty indices of higher ethical orders simply by increasing the value of $\alpha$ and $\beta$ and hence giving simultaneously more weight to $\mathrm{VE}$ and $\mathrm{HI}$ (since increasing $\alpha$ and $\beta$ will not affect $\Delta L(z)$ ).

\section{Statistical procedure}

It will generally be the case that the sample data available to carry out the type of analysis described above will have been drawn from a continuous ${ }^{17}$ joint population distribution of pre-policy and post-policy incomes. Because of this, the probability of observing exact pre-policy equals in any sample would appear to be very small. Using sample data to estimate classical HI would thus seem problematic. This has been known for a long time as the "identification of equals" problem.

As in Duclos and Lambert (2000), however, we suggest tackling this problem through a non-parametric estimation of the joint distribution of pre-policy and post-policy incomes. In practice, this is done below using kernel density estimation with a Gaussian kernel and a bandwidth-selection procedure suggested by Silverman (1986). The method is described in some detail in Duclos and Lambert (2000). For a hint of the procedure, let the estimator of the conditional density of post-policy $i$ 's income given $y_{h}, f^{i}\left(y \mid y_{h}\right)$, be given by $\hat{f}^{i}\left(y \mid y_{h}\right)$. We then estimate $\gamma_{\beta}^{i}\left(y_{h}, z\right)$ by numerical integration through

$$
\hat{\gamma}_{\beta}^{i}\left(y_{h}, z\right)=\left(\int_{0}^{z}(z-y)^{\beta} \hat{f}^{i}\left(y \mid y_{h}\right) d y\right)^{1 / \beta} .
$$

Estimators of the objects $\eta_{\beta}^{i}\left(y_{h}, z\right), H_{\beta}^{i}(z), C_{\alpha, \beta}^{* i}(z), V_{\alpha, \beta}^{i}(z)$, and $E_{\alpha, \beta}^{i}(z)$ follow naturally after computing $\hat{\gamma}_{\beta}^{i}\left(y_{h}, z\right)$ at each point $y_{h}$ observed in the data. Note that expressions like $\Gamma_{\alpha}(\mathbf{g}(z)), C_{\alpha}(\mathbf{g}(z)), L^{i}(z)$ and $E_{\alpha}^{i}(z)$ can be estimated straightforwardly from the empirical or sample distributions of pre- and post-policy incomes.

\section{An application to Tunisia}

We illustrate the use of the methodology presented above using a 1990 Tunisian survey, "Enquête Nationale sur le Budget et la Consommation des Ménages 1990"

\footnotetext{
${ }^{17}$ Approximately so, at least in the case of large populations.
} 
(National Household Budget and Expenditure Survey). This household survey is multipurpose and provides reliable information on consumption expenditures for various items as well as extensive socio-demographic information on 7734 households. The survey does not, however, include information on incomes. We thus use total household expenditure (divided by household size) for valuing and comparing individual well-being in our Tunisian data. Note also that we suppose that this initial distribution of well-being is horizontally equitable 18 .

The main anti-poverty program currently in force in Tunisia is based on the subsidization of food consumption and thus on "commodity targeting". 19 Government expenditures on that program have been substantial throughout the 1980's and the 1990's, amounting to $4.1 \%$ of GDP in $1984,2.9 \%$ in 1990 , and $2 \%$ in 1995. It would thus seem instructive to compare the outcome of this program with that of an alternative one based, for instance, on targeting by socio-demographic indicators - referred to as "socio-demographic targeting" in this paper. For this, we use here an illustrative socio-demographic targeting program that involves household proxy-means tests subject to the same aggregate budget as that for commodity targeting. The program first estimates an ordinary-least-squares model to predict households' income using easily observable variables, namely, the region of residence and the demographic structure of the households. The program then assigns to the household with the highest predicted poverty gap a per capita transfer that lowers its poverty gap to the next highest one. This is followed by a transfer to these first two households that lowers their predicted poverty gap to that of the next poorest household. This pattern is repeated until all available funds are disbursed. This procedure yields a detailed schedule of transfers that depend on observable socio-demographic characteristics.

Comparing the outcomes of commodity and socio-demographic targeting requires an estimator of individual well-being that is sensitive to price variations. Following King's (1983b) methodology, we use a vector of reference prices to compute a distribution of real (or "equivalent") incomes under commodity targeting (policy 1) as well as under socio-demographic targeting (policy 2). The reference prices are given by those in the absence of the policies, viz, by those prices that we suppose would prevail in the absence of any of these anti-poverty programs. To compute equivalent incomes and the size of the deadweight losses, we use the results of Bibi's (2002b) estimation of a Tunisian commodity demand

\footnotetext{
${ }^{18}$ For alternative assumptions, see inter alia Atkinson (1979), Lerman and Yitzhaki (1995), and Kaplow $(1989,1995)$

${ }^{19}$ Details about this program can be found in Tuck and Lindert (1996). See also World Bank (1995).
} 
system, which found that the aggregate deadweight loss amounts to approximately $16.7 \%$ of the total food subsidy budget. A real per capita poverty line $z$ of 360 Tunisian Dinars (TD) per year is used as a reference line. This corresponds to approximately $50 \%$ of mean expenditure and is roughly equal to the often-used US\$1-a-day line. For expositional convenience, we normalize all of this section's money-metric indicators by that poverty line.

Figure 2 shows a scatter-plot distribution of equivalent incomes under commodity targeting (the " + " distribution) and socio-demographic targeting (the points linked by lines). Pre-policy incomes are expressed as a proportion of the reference poverty line. The thickness of the 45-degree line is explained by the presence of many households who receive no benefit from socio-demographic targeting. HI occurs whenever data points on this scatter plot are vertically aligned. A quick look at Figure 2 shows immediately that socio-demographic targeting violates $\mathrm{HE}$ considerably more than commodity targeting. In other words, at some given level of well-being, there is less variability in the impact of commodity targeting than in that of socio-demographic targeting. Said differently, the differences in sociodemographic indicators are larger than those in food consumption at a given level of well-being. This is in fact reminiscent of the difficulties faced by the (small) existing socio-demographic targeting programs in Tunisia, alluded to for instance in World Bank (1995): "(Their) coverage is still inadequate. As a result, many of the truly needy do not benefit from the program, while others receive multiple benefits from various social assistance and insurance programs."

Although HI would appear more important under socio-demographic targeting than under commodity targeting, Figure 2 also suggests that the expected income at each pre-policy income level up to $z$ is always higher under socio-demographic targeting than under commodity targeting - the local averages of the +'s are higher than the local averages of the points linked by the lines. This is confirmed by Figure 3, where the top line (the one with the "+") shows at different pre-policy income the expected benefit under socio-demographic targeting, and where the line with the "o" shows the expected benefit under commodity targeting. Targeting by socio-demographic indicators would therefore look more supportive of the poor in general, and more supportive of the very poor in particular. Because of this, it would seem to be vertically more equitable and also to cause lower leakages.

Quantitative estimates of the overall comparative policy effectiveness of the two targeting schemes are summarized in Table 1. All numbers are expressed as a percentage of the reference poverty line. The initial average poverty gap is $9.9 \%$ of the poverty line. It is reduced to $7.87 \%$ under commodity targeting and to $5.78 \%$ under socio-demographic targeting. Commodity targeting therefore 
involves significantly greater leakages (almost 50\% more), as shown on the second line.

The next three lines of Table 1 quantify the difference in the HI costs of the two programmes for three different values of $\beta=2,4,8$. The larger the aversion to HI, the more negative is that difference, thus capturing the fact that socio-demographic targeting is judged less and less desirable as the policymaker's ethical dislike for treating equals unequally is increased. For $\beta$ equal to or greater than 4 , the higher cost of $\mathrm{HI}$ for socio-demographic targeting (relative to commodity targeting) outweighs that scheme's lower leakage rate.

As suspected above, the following lines show, however, that socio-demographic targeting is vertically more equitable than commodity targeting. Recall from (3) that when $\alpha=\beta$, no separate ethical weight to $\mathrm{HI}$ is given: all that matters from a re-distributive point of view is the size of the vertical distances between individuals, and HI matters only in so much as it increases such distances. From (16), the cost of inequality when $\alpha=\beta=2$ for instance is reduced by $V_{2,2}^{i}(z)-H_{2}^{i}(z)$. Added to the fact that it involves lower leakages, this greater vertical effectiveness of socio-demographic targeting leads to greater policy effectiveness $E_{2,2}^{i}$ for that type of targeting. Socio-demographic targeting is therefore judged to be the more effective of the two schemes when violations of HI are not granted separate ethical importance.

This is confirmed by the stochastic dominance tests of Figure 4. Figure 4 compares the difference between the cumulative benefits of socio-demographic and commodity targeting over a bottom range of poverty lines that extends well beyond the reference line (which is shown as $100 \%$ on the Figure). The cumulative benefits of socio-demographic targeting always exceed substantially those of commodity targeting over the range of poverty lines up to the reference one. Said differently, since the outlays on the two programs are the same, the rate of leakage for commodity targeting always exceeds that for socio-demographic targeting whenever a poverty line less than or equal to the reference line is used. Sociodemographic targeting is therefore second-order poverty dominant. This also means that socio-demographic targeting will always be judged policy-superior whenever the measure $\Delta E_{\alpha, \alpha}(z)$ is computed for any $\alpha \geq 1$ and for any $z$ lower than or equal to our reference poverty line (in fact, for any $z$ on the Figure).

Such stochastic dominance tests (and standard poverty analysis) impose that $\alpha=\beta$ and $d o$ not, therefore, give HI "any independent content" (recall Auerbach and Hasset's quote). To show why giving HI independent ethical content can matter, consider Figure 5, which displays the local cost of HI at different poverty lines for $\beta=4$. That cost is clearly much greater under socio-demographic targeting 
than under commodity targeting. Figure 3 also shows the expected benefit under both targeting schemes net of the money-metric ethical cost of HI, and this, using $\beta=4$. The line with the " $\diamond$ " shows that information for commodity targeting, and the line with the " $\times$ " shows it for socio-demographic targeting. These two lines thus give

$$
\left[\left(z-y_{h}\right)-\gamma_{1}^{i}\left(y_{h}, z\right)\right]-\eta_{\beta}^{i}\left(y_{h}, z\right)
$$

for each of the two policies, $\left[\left(z-y_{h}\right)-\gamma_{1}^{i}\left(y_{h}, z\right)\right]$ being the average fall in the local poverty gap, and $\eta_{\beta}^{i}\left(y_{h}, z\right)$ being the local cost of HI. Note that the superiority of socio-demographic targeting is greatly reduced by the cost of HI. In fact, if no weight to VE is given, then with $\beta=4$ commodity targeting is judged to be more policy effective than socio-demographic targeting - this can be seen from the fact that $\Delta E_{1,4}(z)=-0.04$ in Table 1 .

Whether socio-demographic or commodity targeting is judged superior thus depends on the policymaker's comparative attitude to VE and HE. Table 1 summarizes this for various combinations of values for $\alpha$ and $\beta$. For relatively low values of $\beta$, socio-demographic targeting is found superior to commodity targeting. The reverse holds for relatively large values of $\beta$ - for instance, both $\Delta E_{1,4}(z)$ and $\Delta E_{2,8}(z)$ are negative. This suggests that the status quo could indeed be deemed preferable to a system of socio-demographic targeting that would nevertheless involve greater vertical equity and lower leakages.

\section{Conclusion}

There is a clearly need among policymakers for meaningful descriptive and normative measures of policy effectiveness for the analysis of poverty alleviation programs. This paper suggests an approach which brings distribution-sensitivity formally into the assessment of such poverty effectiveness. The methodology is intended to complement the common use of two crude indices, the under-coverage and the leakage ratios. An important feature of it is its formal integration of horizontal and vertical equity criteria. The policy effectiveness measures are decomposable into leakage, vertical and horizontal components. They provide moneymetric measures of the social impact of anti-poverty programs that can be useful both for descriptive and normative purposes.

The use of these measures is illustrated using Tunisian households' data and two alternative targeting schemes. The first scheme, which is currently in force, awards benefits to the poor through foodstuff subsidization. The second scheme targets transfers on the basis of easily observable socio-demographic indicators. 
The results show that, although commodity targeting involves higher leakages and lower vertical equity, the fact that it is less horizontally inequitable than sociodemographic targeting may render it preferable for policy purposes. Hence, taking horizontal equity seriously can have important implications for the design and the understanding of poverty alleviation policies.

\section{References}

[1] Adams R. H. (2000), Self-Targeted Subsidies: The Distributional Impact of the Egyptian Food Subsidy System. Working paper number 2322, The World Bank.

[2] Atkinson, A. B. (1970), On the Measurement of Inequality, Journal of Economic Theory 2, 244-263.

[3] Atkinson, A. B. (1979), Horizontal Equity and the Distribution of the Tax Burden, in H.J. Aaron and M.J. Boskin (eds.), The Economics of Taxation, chap. 1, Brookings Institution, Washington DC., 318.

[4] Atkinson, A. B. (1987), On the Measurement of Poverty, Econometrica 55, 749-764.

[5] Atkinson, A. B. (1995), On Targeting Social Security: Theory and Western Experience with Family Benefits, in: Dominique Van de Walle and Kimberly Nead (eds.), Public Spending and the Poor, Theory and Evidence. The Johns Hopkins University Press, The World Bank, Washington, DC.

[6] Auerbach, A. J. and K. A. Hasset (2002), A New Measure of Horizontal Inequality, American Economic Reviw, vol. 92 (4), 1116-1125.

[7] Balcer, Y. and E. Sadka (1986). Equivalence Scales, Horizontal Equity and Optimal Taxation Under Utilitarianism, Journal of Public Economics, 29 (1), 7997.

[8] Beckerman, W. (1979), The impact of Income Maintenance Payments on Poverty in Britain, 1975. Economic Journal, vol. 89, pp. 261-279.

[9] Bibi, S. (2002a), Does the Specification of a New Class of Poverty Measures Matter? Evidence from Tunisia, paper presented at the 27th General Confer- 
ence of The International Association for Research in Income and Wealth, Stockholm, August 18 - 24, 2002, Sweden.

[10] Bibi, S. (2002b), On the Impact of Better Targeted Transfers on Poverty in Tunisia, CIRPEE working paper \# 0203.

[11] Blackorby, C., D. Donaldson and A. Auersperg (1981), Ethical Social Index Numbers and the Measurement of Effective Tax / Benefit Progressivity. Canadian Journal of Economics, vol. 17, 683-694.

[12] Chakravaty, S. R. and D. Mookherjee (1998), Optimal Subsidy for the Poor. Economics Letters. vol. 61, 313-319.

[13] Cornia, G. A. and F. Stewart (1995), Two Errors of Targeting. In: Dominique Van de Walle and Kimberly Nead (eds.), Public Spending and the Poor, Theory and Evidence. The Johns Hopkins University Press, The World Bank, Washington, DC.

[14] Creedy, J. (1996), Comparing Tax and Transfer System: Poverty, Inequality and Target Efficiency. Economica, vol. 63 (250S), pp. 163-174.

[15] Davidson, R., and J.-Y. Duclos (2000), Statistical Inference for Stochastic Dominance and for the Mesearement of Poverty and Inequality, Econometrica, vol. 68, 1435-1465.

[16] Duclos, J.-Y. (1995), Modelling the Take-up of State Support, Journal of Public Economics, vol.58, (3), 391-415.

[17] Duclos, J.-Y., V. Jalber, and A. Araar (2002), Classical Horizontal Inequity and Reranking: an Integrating Approach, forthcoming in Research on Economic Inequality.

[18] Duclos, J.-Y. and P. J. Lambert (2000), A Normative Approach to Measuring Classical Horizontal Inequity. Canadian Journal of Economics, vol. 33, 87113.

[19] Duclos, J.Y., and P. Makdissi (2002), Restricted and Unrestricted Dominance for Welfare, Inequality and Poverty Orderings, Working paper 00-01, Department of Economics, Université Laval, and forthcoming in Journal of Public Economic Theory. 
[20] Feldstein, M. (1976), On the Theory of Tax Reform. Journal of Public Economics, vol. 62, 77-104.

[21] Festinger, L. (1954), A Theory of Social Comparison Processes, Human Relations, vol. 7, 117-140.

[22] Foster, J. E. (1984), On Economic Poverty: A Survey of Aggregate Measures. Advances in Econometrics, vol. 3, 215-251.

[23] Foster, J. E., J. Greer and E. Thorbecke (1984), A Class of Decomposable Poverty Measures. Econometrica, vol. 52, 761-765.

[24] Foster, J. E. and A. F. Shorroks (1988), Poverty Orderings. Econometrica, vol. 56, 173-177.

[25] Grosh, M. E. and Baker, J. L. (1995), Proxy Means Tests for Targeting Social Programs: Simulations and Speculation. LSMS Working Paper number 118. The World Bank.

[26] Hettich, W. (1983), Reform of the Tax Base and Horizontal Equity, National Tax Journal, 36 (4), 417-427.

[27] Jalan, J., and M. Ravallion (1998), Are There Dynamic Gains from PoorArea Development Program? Journal of Public Economics, vol. 67 (1), 6585 .

[28] Jenkins, S. P. and P. J. Lambert (1997), Three ' $i$ 's of Poverty Curves, with an Analysis of UK Poverty Trends. Oxford Economic Papers. vol. 49, 317-327.

[29] Jenkins, S., and P.J. Lambert (1999), Horizontal inequity measurement: a basic reassessment, ch. 18 in Handbook of Income Inequality Measurement, J. Silber ed., Kluwer Academic Publishers, 535-556.

[30] Kaplow, L. (1989), Horizontal Equity: Measures in Search of a Principle. National Tax Journal, vol. 42, 139-154.

[31] Kaplow, L. (1995). A Fundamental Objection to Tax Equity Norms: A Call for Utili-tarianism, National Tax Journal, 48 (4), 497-514.

[32] King, M. A. (1983a), An Index of Inequality: With Applications to Horizontal Equity and Social Mobility. Econometrica, vol. 51, 99-115. 
[33] King, M. A. (1983b), Welfare Analysis of Tax Reforms using Household Data. Journal of Public Economics vol. 21, 183-214.

[34] Kolm, S. C. (1969), The Optimal Production of Social Justice, in Margolis, J. and H Guitton (eds.), Public Economics. London: Macmillan.

[35] Lambert, P. J. and X. Ramos (1997), Horizontal Inequity and Vertical Redistribution. International Tax and Public Finance, vol. 4, 25-37.

[36] Lerman, R. I. and S. Yitzhaki (1995). Changing Ranks and the Inequality Impacts of Taxes and Transfers, National Tax Journal, 48 (1), 45-59.

[37] Musgrave, R. A., (1959), The Theory of Public Finance, McGraw-Hill, NewYork.

[38] Musgrave, R. A., (1990), Horizontal Equity, Once More. National Tax Journal, vol.43, 113-122.

[39] Narayan, D. and P. Petesch. (2002), Voices of the Poor: From Many Lands. New York, N.Y: Published for the World Bank, Oxford University Press.

[40] Nozick, R. (1974), Anarchy, State and Utopia, Basil Blackwell, Oxford.

[41] Park, A., S. Wang , and G. Wu. (2002), Regional Poverty Targeting in China, Journal of Public Economics, vol. 86, 123-153.

[42] Plotnick, R. (1981), A Measure of Horizontal Inequity. Review of Economics and Statistics, vol. 63, 283-288.

[43] Plotnick, R. (1982), The Concept and Measurement of Horizontal Inequity. Journal of Public Economics, vol.17, 373-391.

[44] Plotnick, R. (1985), A Comparison of Measures of Horizontal Inequity, in Martin David et Timothy Smeeding (eds.), Horizontal Equity, Uncertainty and Economic Well-Being, The University of Chicago Press, Chicago, 239268.

[45] Plotnick, R. (1999), Comments on "Horizontal inequity measurement: a basic reassessment" by S. Jenkins and P. Lambert, ch. 18 in Handbook of Income Inequality Measurement, J. Silber ed., Kluwer Academic Publishers, 554-556. 
[46] Ravallion, M. (1993), Poverty Alleviation Through regional Targeting: A Case Study for Indonesia", in Hoff, K., A Braverman and J. Stiglitz (eds.), The Economics of Rural Organization: Theory, Practice and Policy. Oxford University Press, Oxford, 453-467.

[47] Ravallion, M. (1994), Poverty Comparisons. Fundamentals of Pure and Applied Economics Series, Harwood Academic Press, New York.

[48] Ravallion, M. (1998), Reaching Poor Areas in a Federal System. Policy research Working Paper, wps 1901, The World Bank.

[49] Ravallion, M. and G. Datt (1995), Is Targeting Through a Work Requirement Efficient? Some Evidence for Rural India. In: Dominique Van de Walle and Kimberly Nead (eds.), Public Spending and the Poor, Theory and Evidence. The Johns Hopkins University Press, The World Bank, Washington, DC.

[50] Rawls, J. (1971), A Theory of Justice. Cambridge, Massachusetts, Havard University Press.

[51] Riskin, C. (1994), Chinese rural poverty: marginalized or dispersed?", American Economic Review, Papers and Proceedings, vol. 84 (2), 281-284.

[52] Runciman, W. G. (1966). Relative Deprivation and Social Justice: A Study of Attitudesto Social Inequality in Twentieth-Century England, Berkeley and Los Angeles, University of California Press.

[53] Schady N. R. (2002), Picking the poor: indicators for geographic targeting in Peru", Review of Income and Wealth, Series 48 (3), 417-434.

[54] Sen, A. K. (1976), Poverty: An Ordinal Approach to Measurement. Econometrica, vol. 44, 219-231.

[55] Silverman, B. W. (1986), Density Estimation for Statistics and Data Analysis. Chapman and Hall, London.

[56] Stiglitz, J. E. (1982), Utilitarianism and Horizontal Equity: The Case for Random Taxation, Journal of Public Economics, 18 (1), 133.

[57] Tuck, L. and K. Lindert (1996), From Universal Food Subsidies to a SelfTargeted Program, A Case Study in Tunisian Reform. World Bank Discussion Paper, no. 351, The World Bank, Washington, DC. 
[58] Watts, H. (1968), An Economic Definition of Poverty. In D. P. Moynihan (ed.), On Understanding Poverty. New York: Basic Books.

[59] Weisbrod, B. A. (1970), Collective Action and the Distribution of Income: A Conceptual Approach. In Haverman, R. H. and Margolis, J. (eds.), Public Expenditure and Policy Analysis. Markham, Chicago.

[60] World Bank (1995) Republic of Tunisia, Poverty Alleviation: Preserving Progress while Preparing for the Future. Middle East and North Africa Region, Report $\mathrm{N}^{\circ} 13993-\mathrm{TUN}$.

[61] Zheng, B. (1997), Aggregate Poverty Measures, Journal of Economic Surveys, vol. 11 (2), 123-63. 


\section{Appendix}

\section{Proof of Theorem 1 .}

Combining (13) and (5), we have that

$$
\begin{aligned}
E_{\alpha, \beta}^{i}(z) & =\Gamma_{\alpha}(\mathbf{g}(z))-\Gamma_{\alpha}\left(\gamma_{\beta}^{i}(z)\right) \\
& =C_{\alpha}(\mathbf{g}(z))+\Gamma_{1}(\mathbf{g}(z))-\left[C_{\alpha}\left(\gamma_{\beta}^{\mathbf{i}}(z)\right)+\Gamma_{1}\left(\gamma_{\beta}^{\mathbf{i}}(z)\right)\right] .
\end{aligned}
$$

Rearranging and using (7), this gives:

$$
\begin{aligned}
E_{\alpha, \beta}^{i}(z)= & \Gamma_{1}(\mathbf{g}(z))-\Gamma_{1}\left(\gamma_{\beta}^{\mathbf{i}}(z)\right)+C_{\alpha}(\mathbf{g}(z))-C_{\alpha}\left(\gamma_{\beta}^{\mathbf{i}}(z)\right) \\
= & \rho-L^{i}(z) \\
& +\Gamma_{1}\left(\mathbf{g}^{i}(z)\right)-\Gamma_{1}\left(\gamma_{\beta}^{\mathbf{i}}(z)\right)+C_{\alpha}(\mathbf{g}(z))-C_{\alpha}\left(\gamma_{\beta}^{\mathbf{i}}(z)\right) .
\end{aligned}
$$

Note from (12) that

$$
V_{\alpha, \beta}^{i}(z)=C_{\alpha}(\mathbf{g}(z))-C_{\alpha}\left(\gamma_{\beta}^{i}(z)\right) .
$$

From (9) and (10), also observe that

$$
\begin{aligned}
H_{\beta}^{i}(z) & =n^{-1} \sum_{h=1}^{N} n_{h} \gamma_{\beta}^{i}\left(y_{h}, z\right)-n^{-1} \sum_{h=1}^{N} n_{h} \gamma_{1}^{i}\left(y_{h}, z\right) \\
& =n^{-1} \sum_{h=1}^{N} \sum_{\Omega\left(y_{h}\right)} \gamma_{\beta}^{i}\left(y_{h}, z\right)-n^{-1} \sum_{h=1}^{N} \sum_{\Omega\left(y_{h}\right)} g_{h}^{i}(z) \\
& =\Gamma_{1}\left(\gamma_{\beta}^{\mathbf{i}}(z)\right)-\Gamma_{1}\left(\mathbf{g}^{i}(z)\right) .
\end{aligned}
$$

Hence, using (28), (29) and (32), Theorem 1 is obtained.

\section{Proofs of some of the remarks of pages 14 to 16 .}

For remark 2, note that $C_{1}(\mathbf{g}(z))=C_{1}\left(\gamma_{1}^{i}(z)\right)=0$, and that $\Gamma_{1}\left(\mathbf{g}^{i}(z)\right)=$ $\Gamma_{1}\left(\gamma_{\mathbf{1}}^{\mathbf{i}}(z)\right)$.

To show (16), first observe from (2), (4) and (8) that

$$
\begin{aligned}
\Gamma_{\alpha}\left(\gamma_{\alpha}^{i}(z)\right) & =\left\{n^{-1} \sum_{h=1}^{N} n_{h}\left[\left(n_{h}^{-1} \sum_{\Omega\left(y_{h}\right)} g_{h}^{i}(z)^{\alpha}\right)^{1 / \alpha}\right]^{\alpha}\right\}^{1 / \alpha} \\
& =\left\{n^{-1} \sum_{h=1}^{N} \sum_{\Omega\left(y_{h}\right)} g_{h}^{i}(z)^{\alpha}\right\}^{1 / \alpha} \\
& =\Gamma_{\alpha}\left(\mathbf{g}^{i}(z)\right) .
\end{aligned}
$$


Using (5),(7) and (13), (16) is then obtained.

For remark 4, observe from (13), (14) and (16) that

$$
\begin{aligned}
E_{\alpha, \beta}^{i}(z)-E_{\alpha, \alpha}^{i}(z) & =V_{\alpha, \beta}^{i}(z)-H_{\beta}^{i}(z)-\left(C_{\alpha}(\mathbf{g}(z))-C_{\alpha}\left(\mathbf{g}^{i}(z)\right)\right) \\
& =\Gamma_{\alpha}\left(\gamma_{\alpha}^{i}(z)\right)-\Gamma_{\alpha}\left(\gamma_{\beta}^{i}(z)\right) .
\end{aligned}
$$

When $\alpha<\beta$, it is clear from the mean of order $\beta$ in $(8)$ that $\left.\gamma_{\alpha}^{i}\left(y_{h}, z\right)\right) \leq$ $\gamma_{\beta}^{i}\left(y_{h}, z\right)$ ) (with a strict inequality whenever there is HI within $\Omega\left(y_{h}\right)$ ). Using (37) and the fact that $\Gamma_{\alpha}(\cdot)$ is increasing in its arguments, this proves (19). The reverse argument proves (20). 
Table 1: Policy effectiveness of two types of targeting in Tunisia (as a \% of the reference poverty line

\begin{tabular}{|c|c|c|c|c|}
\hline \hline & Benchmark & $\begin{array}{c}\text { Commodity } \\
\text { targeting }\end{array}$ & $\begin{array}{c}\text { Socio-demographic } \\
\text { targeting }\end{array}$ & $\begin{array}{c}\text { Outcome } \\
\text { difference }\end{array}$ \\
\hline \hline$\Gamma_{1}(y, z)$ & 9.90 & 7.87 & 5.78 & -2.09 \\
\hline$L(z)$ & - & 7.63 & 5.54 & -2.09 \\
\hline$H_{2}(z)$ & 0 & 0.08 & 1.02 & 0.94 \\
\hline$H_{4}(z)$ & 0 & 0.20 & 2.32 & 2.12 \\
\hline$H_{8}(z)$ & 0 & 0.39 & 3.88 & 3.49 \\
\hline$V_{2,2}(z)$ & - & 0.88 & 3.54 & 2.66 \\
\hline$V_{2,4}(z)$ & - & 0.89 & 2.28 & 1.39 \\
\hline$V_{2,8}(z)$ & - & 0.88 & 0.72 & -0.16 \\
\hline$E_{1,1}(z)$ & - & 2.03 & 4.12 & 2.09 \\
\hline$E_{1,2}(z)$ & - & 1.95 & 3.10 & 1.15 \\
\hline$E_{1,4}(z)$ & - & 1.83 & 1.79 & -0.04 \\
\hline$E_{2,2}(z)$ & - & 2.83 & 6.63 & 3.80 \\
\hline$E_{2,4}(z)$ & - & 2.72 & 4.08 & 1.36 \\
\hline$E_{2,8}(z)$ & - & 2.52 & 0.96 & -1.56 \\
\hline \hline
\end{tabular}


Figure 1: Poverty gaps and the cost of inequality

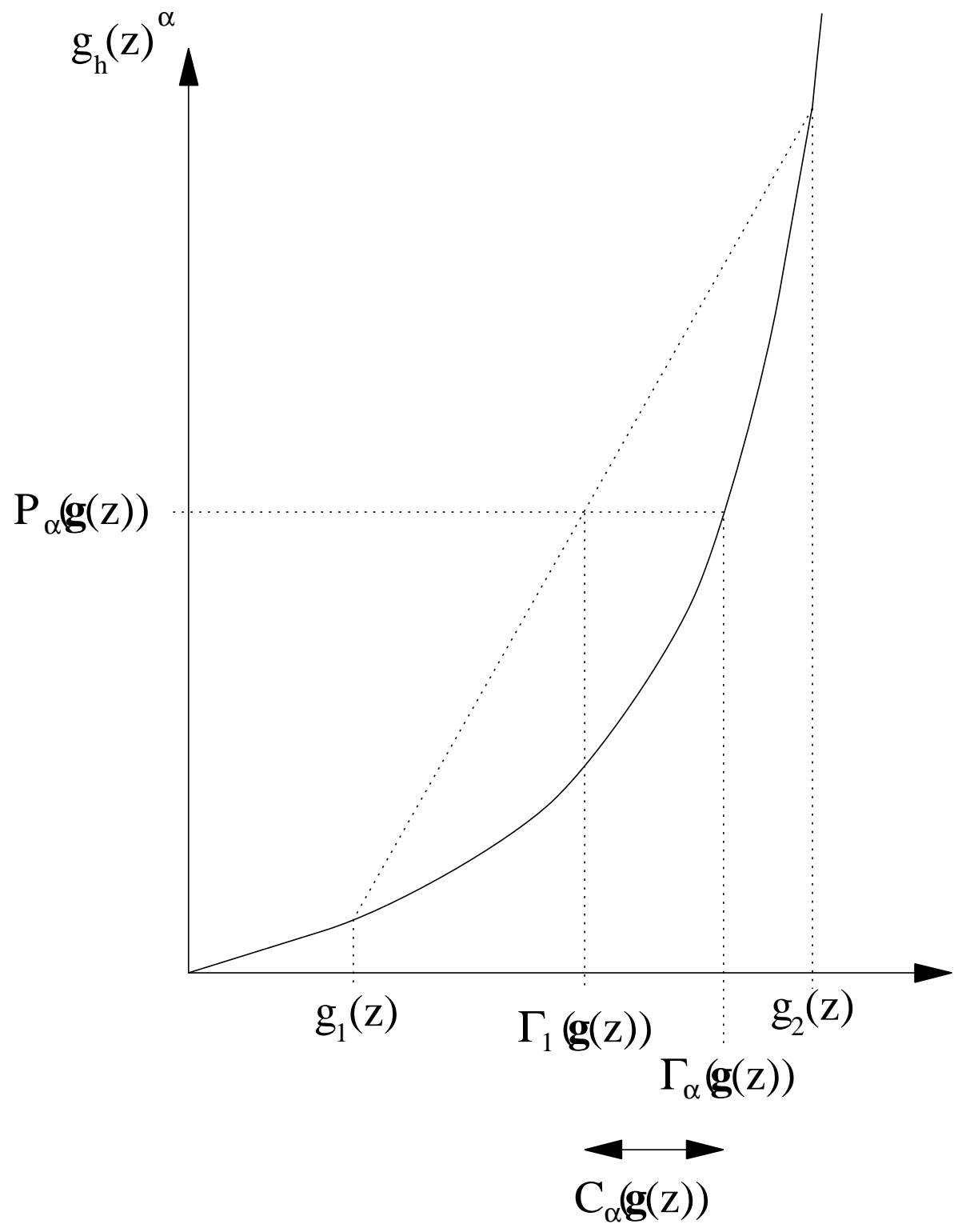




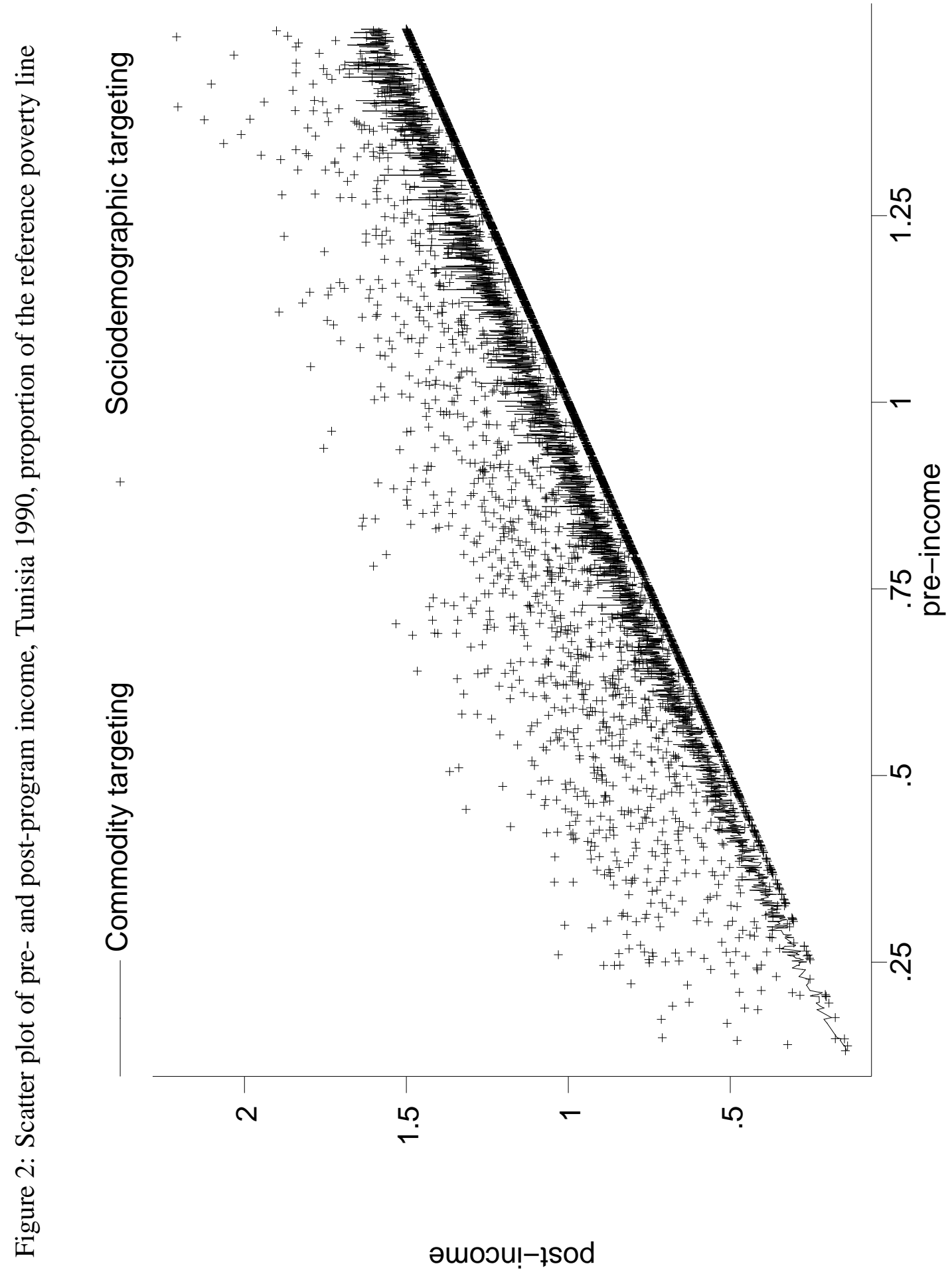




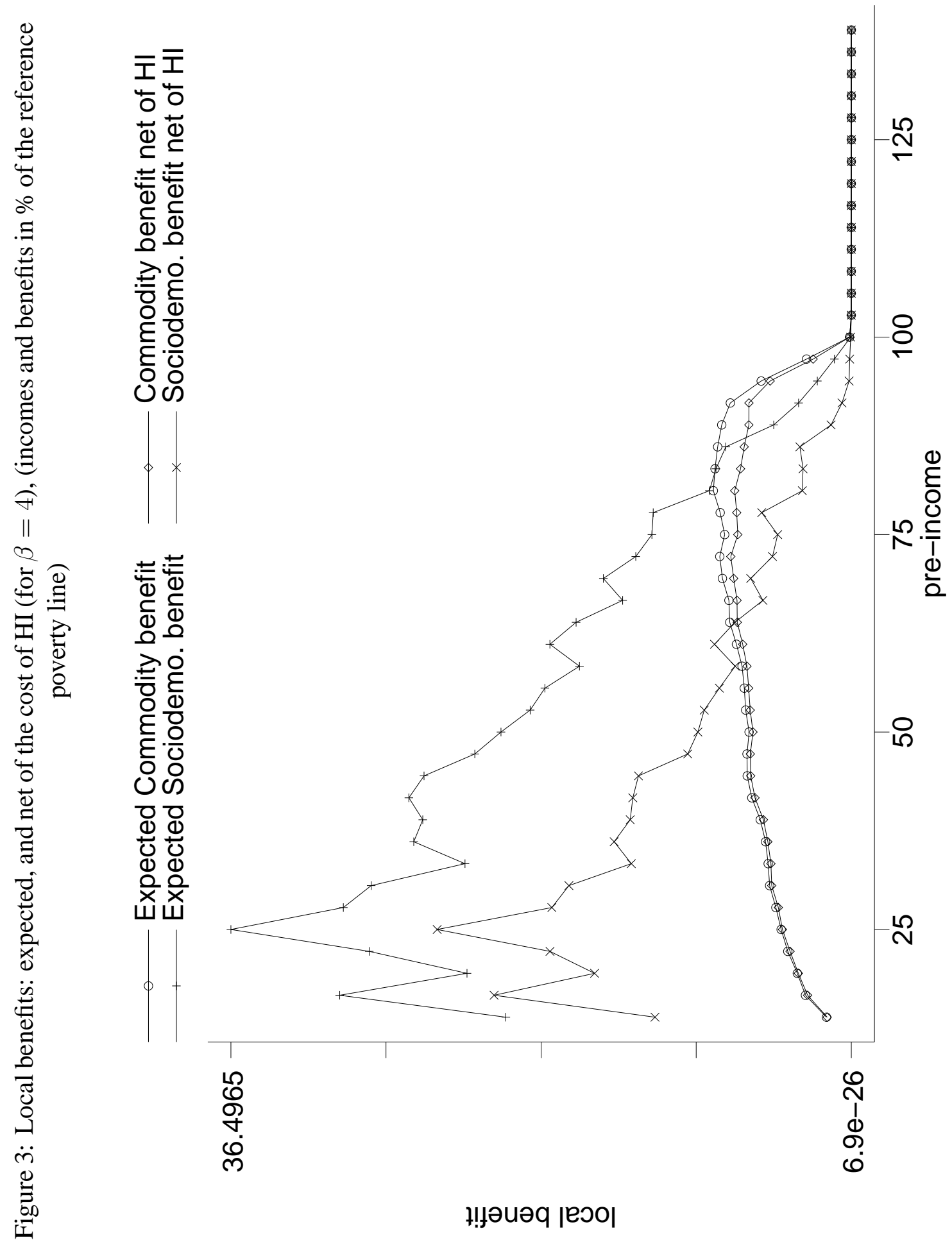




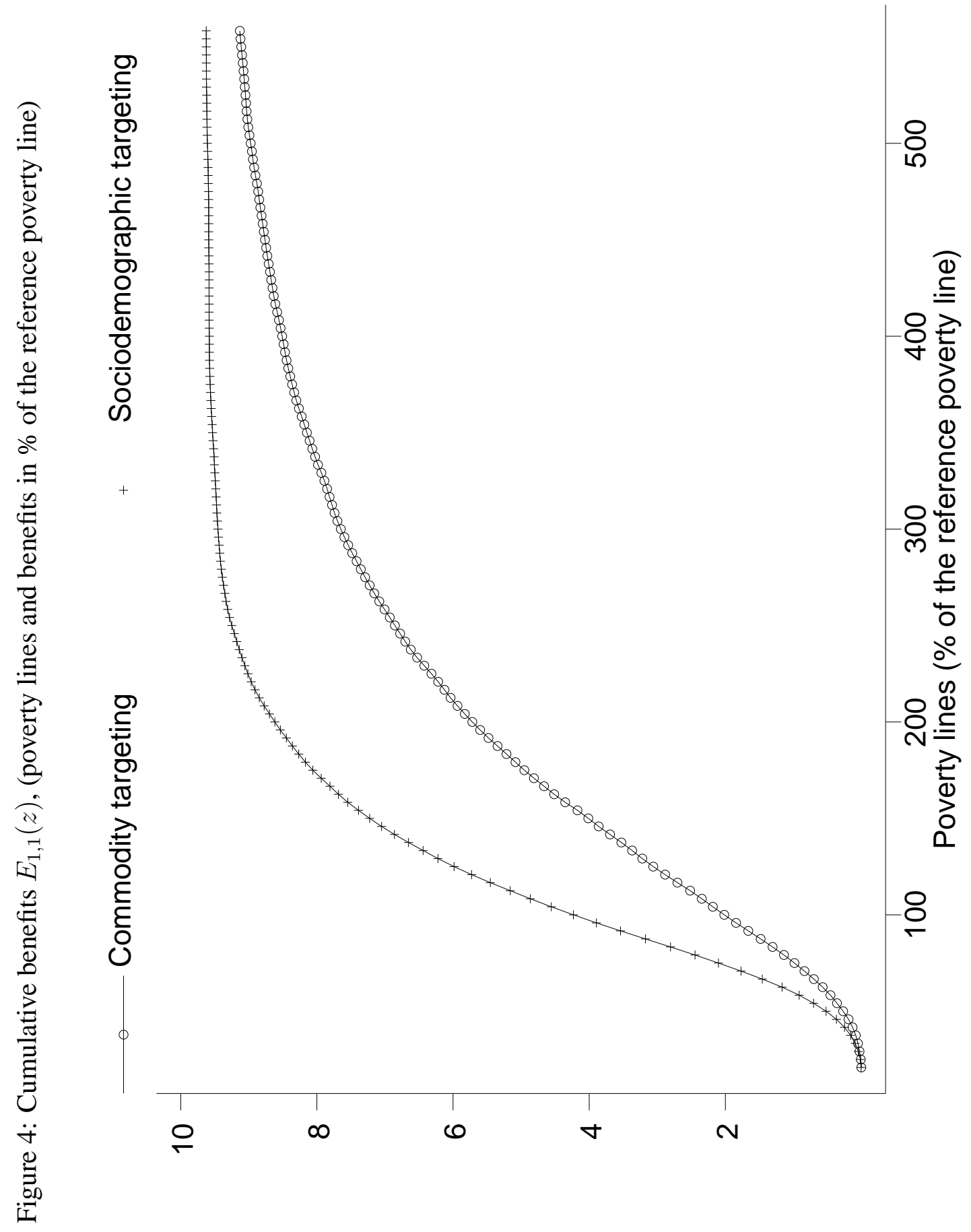

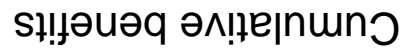




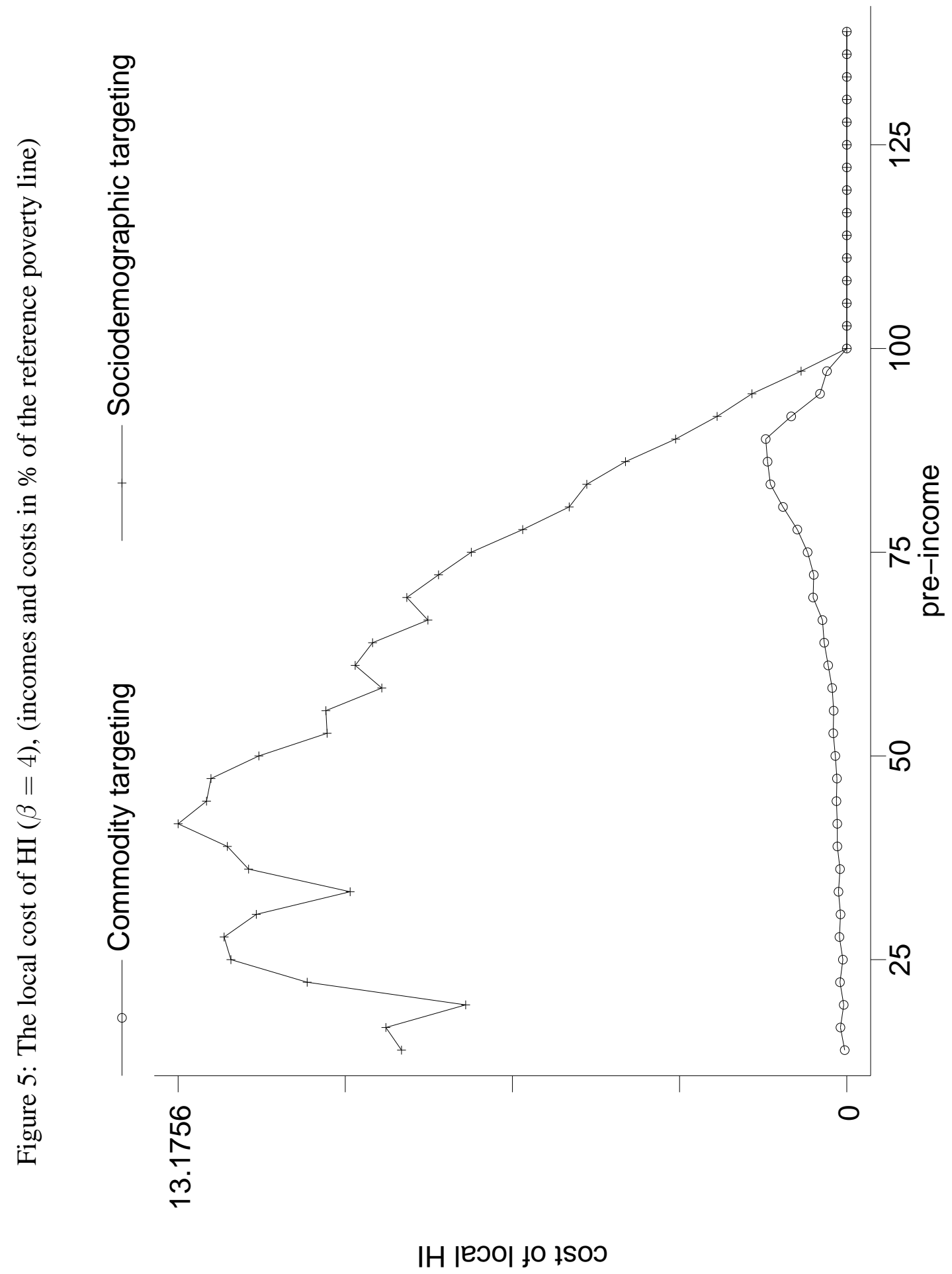

